\title{
Determination of Acquired Resistance Profiles of Pseudomonas aeruginosa Isolates and Characterization of an Effective Bacteriocin-Like Inhibitory Substance (BLIS) Against These Isolates
}

\author{
Dariush Shokri, ${ }^{1}$ Mohammad Rabbani Khorasgani, ${ }^{1,}$ Saeideh Zaghian, ${ }^{2}$ Seyed Masih Fatemi, ${ }^{3}$ Milad \\ Mohkam, ${ }^{4}$ Younes Ghasemi, ${ }^{4}$ and Asghar Taheri-Kafrani ${ }^{5}$ \\ ${ }^{1}$ Department of Biology, Faculty of Sciences, University of Isfahan, Isfahan, IR Iran \\ ${ }^{2}$ Nanobiotechnology Department, Faculty of Biological Sciences, Tarbiat Modares University, Tehran, IR Iran \\ ${ }^{3}$ Department of Microbiology, Faculty of Basic Sciences, Shahrekord Branch, Islamic Azad University, Shahrekord, IR Iran \\ ${ }^{4}$ Department of Pharmaceutical Biotechnology, Pharmaceutical Sciences Research Center, Faculty of Pharmacy, Shiraz University of Medical Sciences, Shiraz, IR Iran \\ ${ }^{5}$ Department of Biotechnology, Faculty of Advanced Sciences and Technologies, University of Isfahan, Isfahan, IR Iran \\ "Corresponding author: Mohammad Rabbani Khorasgani, Department of Biology, Faculty of Sciences, University of Isfahan, Isfahan, IR Iran. Tel: +98-03137932480, Fax: \\ +98-3137932456, E-mail: m.rabbani@biol.ui.ac.ir
}

Received 2015 September 01; Revised 2015 December 25; Accepted 2016 April 18.

\begin{abstract}
Background: The emergence of pan-drug resistant strains (PDR) of Pseudomonas aeruginosa has led to renewed efforts to identify alternative agents, such as bacteriocins and bacteriocin-like inhibitory substances (BLISs).

Objectives: The aims of this study were to determine the acquired resistance profiles of multidrug-resistant (MDR), extensively drug-resistant (XDR), and PDR P. aeruginosa isolates based on the revised definitions of the CDC and ECDC and to screen and characterize effective BLISs against these isolates.

Patients and Materials: In a cross-sectional study, 96 P. aeruginosa strains were isolated during a 12-month period. The resistance profiles of these isolates were determined as MDR, XDR, and PDR, and the data were analyzed using WHONET5.6 software. A BLIS against the $P$. aeruginosa strains was characterized based on its physicochemical properties, size, growth curves, and production profiles.

Results: Among the 96 isolates of P. aeruginosa, 2 (2.1\%), 94 (97.9\%), and 63 (65.6\%) were non-MDR, MDR, and XDR, respectively, and $1(1.1 \%)$ was PDR. The most effective antibiotics against these isolates were polymyxins and fosfomycin. A BLIS isolated from the $P$. aeruginosa DSH22 strain had potent activity against 92 (95.8\%) of the 96 isolates. The BLIS was heat stable, (up to $100^{\circ} \mathrm{C}$ for $10 \mathrm{~min}$ ), UV stable, and active within a pH range of 3 - 9 . The activity of BLIS disappeared when treated with trypsin, proteinase K, and pepsin, indicating its proteinous nature. Based on its size ( $25 \mathrm{kDa})$, the BLIS may belong to the large colicin-like bacteriocin family. BLIS production started in the midexponential phase of growth, and the maximum level $(2700 \mathrm{AU} / \mathrm{mL})$ occurred in the late-stationary phase after 25 hours of incubation at $30^{\circ} \mathrm{C}$.

Conclusions: This BLIS with broad-spectrum activity may be a potential agent for the treatment or control of drug-resistant strains of $P$. aeruginosa infection.
\end{abstract}

Keywords: Antibiotic Resistance, Bacteriocin-Like Inhibitory Substance, Multidrug Resistant (MDR), Pseudomonas aeruginosa

\section{Background}

Pseudomonas aeruginosa is an important cause of infection, especially in patients with compromised host defense mechanisms (1). It is the most common pathogen isolated from patients who have been hospitalized longer than 1 week, and it is a frequent cause of nosocomial infections (2-4). Pseudomonas aeruginosa infections, like those caused by many other hospital bacteria, are becoming more difficult to treat because of increased numbers of antibioticresistant strains (2). The emergence of pan-drug resistant (PDR) strains (i.e., strains of a pathogen that are untreatable with current antibiotics) has renewed efforts to identify and develop antibacterial agents that are active against them.

Bacteriocins and bacteriocin-like inhibitory substances (BLISs), which are produced by a wide range of bacteria, may be an alternative to antibiotic treatment $(5,6)$. Bacteriocins and BLISs are bacterial inhibitors, with bactericidal activity that is usually directed against species that are usually closely linked to the producer microorganisms $(2,7)$. These peptides are structurally and functionally diverse groups within the antimicrobial agents were considered as alternatives for antibiotics in resistant bacteria. Bacteriocins (named pyocins) produced by Pseudomonas spp. have been extensively studied (8-12), but the isolation of a bacteriocin with broad-spectrum 
activity against multidrug-resistant (MDR) Pseudomonas has been rarely reported (13).

In 2011, the European centre for disease prevention and control (ECDC) and the centers for disease control and prevention (CDC) defined acquired resistance profiles of $P$. aeruginosa strains as MDR, extensively drug resistant (XDR), and PDR (14). These strains, which are resistant to antibiotic agents, cause serious diseases and are an important public health problem. Controlling these bacteria using new strategies and discovering new antimicrobial agents, such as bacteriocin and BLISs, has been considered by some researchers (15).

\section{Objectives}

The aims of this study were to determine the acquired resistance profiles of $P$. aeruginosa strains based on the new definitions of the ECDC and CDC and to identify bacteriocins with antimicrobial activity against these resistant bacteria, especially PDR isolates, for which no antibiotics exist.

\section{Patients and Methods}

\subsection{Sample Collection and Identification of Collected Isolates}

Samples were collected from clinical specimens submitted for bacterial culture at the microbiology laboratory of Al-Zahra hospital in Isfahan, Iran from March 2013 to March 2014. The specimens included respiratory samples (tracheal aspiration, bronchoalveolar lavage, and bronchial), blood, urine, peritoneal fluid, plural fluid, CSF, and wound discharge They were cultured on blood agar and EMB media (HiMedia Company, India) and incubated at $35^{\circ} \mathrm{C}$ for $18-24$ hours. Pure isolates were identified using gram staining and biochemical tests (16).

\subsection{Determination of the Antimicrobial Resistance Profiles of the $P$. aeruginosa Isolates}

The antimicrobial resistance profiles of the $P$. aeruginosa isolates were based on the CDC and ECDC definitions of MDR, XDR, and PDR (14). An MDR isolate was defined as one that was not susceptible to at least one agent in three or more antimicrobial categories. An XDR isolate was defined as being nonsusceptible to at least one agent in all but two or fewer antimicrobial categories (i.e., bacterial isolates remained susceptible to only one or two categories). Nonsusceptibility to all agents in all antimicrobial categories (i.e., no agents tested as susceptible) was defined as PDR. The antimicrobial categories and agents used were as described by Magiorakos et al. (14) and according to the clinical laboratory standard institute (CLSI
2014) recommendation (17) (Table 1). Kirby-Bauer's disc diffusion method on Mueller-Hinton agar was used for determination of the antibiotic sensitivity pattern. All antimicrobial disks were obtained from the MAST Company, U.K. As recommended by the CLSI (17), P. aeruginosa ATCC 278531, Staphylococcus aureus ATCC 25923, and Escherichia coli ATCC 25922 were used for disc quality control. The plates were incubated at $35^{\circ} \mathrm{C}$ for 18 hours. The diameter of the zone of inhibition was measured, and the degree of susceptibility of the test isolate to each antibiotic was interpreted as sensitive ( $S$ ), intermediate resistant (I), or resistant (R). The data were analyzed using WHONET 5.6 software.

Table 1. Antimicrobials and Agents Used to Define PDR, XDR, and MDR in Pseudomonas aeruginosa Strains (5)

\begin{tabular}{|c|c|c|}
\hline Antimicrobials & Antimicrobial Agent & Amount, $\mu \mathbf{g}$ \\
\hline \multicolumn{3}{|l|}{ Aminoglycosides } \\
\hline & GEN: Gentamicin & 10 \\
\hline & AMK: Amikacin & 30 \\
\hline & NET: Netilmicin & 30 \\
\hline & TOB: Tobramycin & 10 \\
\hline \multicolumn{3}{|l|}{$\begin{array}{l}\text { Antipseudomonal } \\
\text { carbapenems }\end{array}$} \\
\hline & IPM: Imipenem & 10 \\
\hline & MEM: Meropenem & 10 \\
\hline & DOR: Doripenem & 10 \\
\hline \multirow{2}{*}{$\begin{array}{l}\text { Antipseudomonal } \\
\text { cephalosporins }\end{array}$} & CAZ: Ceftazidime & 30 \\
\hline & FEP: Cefepime & 30 \\
\hline \multicolumn{3}{|l|}{$\begin{array}{l}\text { Antipseudomonal } \\
\text { fluoroquinolones }\end{array}$} \\
\hline & CIP: Ciprofloxacin & 5 \\
\hline & LVX: Levofloxacin & 5 \\
\hline \multicolumn{3}{|c|}{$\begin{array}{l}\text { Antipseudomonal } \\
\text { penicillin+ ß-lactamase } \\
\text { inhibitors }\end{array}$} \\
\hline & $\begin{array}{l}\text { TCC: Ticarcillin-clavulanic } \\
\text { acid }\end{array}$ & 75.10 \\
\hline & $\begin{array}{c}\text { TZP: } \\
\text { Piperacillin-tazobactam }\end{array}$ & 100.10 \\
\hline Monobactams & ATM: Aztreonam & 30 \\
\hline Phosphonic acids & FOS: Fosfomycin & 200 \\
\hline \multicolumn{3}{|l|}{ Polymyxins } \\
\hline & COL: Colistin & 10 \\
\hline & POL: Polymyxin B & 300 units \\
\hline
\end{tabular}




\subsection{Screening of Antimicrobial Agent Production by the Isolates}

A qualitative bioassay was performed using the spoton-lawn method for antimicrobial potency production, as follows: The medium consisted of trypticase soy broth, supplemented with $0.6 \%$ yeast extract, without glucose and $1.5 \%$ agar. The medium was spotted with $2 \mu \mathrm{L}$ of the isolated strains and incubated at $30^{\circ} \mathrm{C}$ for 24 hours. The incubated agar plates were overlaid with a soft-agar medium seeded with $107 / \mathrm{mL}$ of the different $P$. aeruginosa strains isolated in this study and P. aeruginosa ATCC 278531, which was used as a standard strain that were tested to determine the $P$. aeruginosa antimicrobial spectrum as indicator. After overnight incubation, the overlaid plates were evaluated for inhibition area observation. Aclear inhibition area of $\geq 3 \mathrm{~mm}$ in diameter was reported as positive, according to Tahiri et al. (18). Screening of the antimicrobial effect of cell-free supernatant was performed according to the method described by Tahiri et al. (18). The antimicrobial production of agents by hospital-isolated pathogens other than P. aeruginosa was also tested. The pathogens tested were Klebsiella spp. (25 strains), Acinetobacter spp., (62 strains) E. coli (38 strains), S. aureus (32 strains), Enterococcus spp. (41 strains), and Listeria monocytogens (3 strains).

\subsection{Identification of a BLIS-Producing Isolate}

The best BLIS-producing isolate was identified initially based on its morphological, culture, and biochemical characteristics, using standard methods (16). The identity of the isolate was then confirmed using a 16SrRNA PCR assay of DNA extracts, with universal primers: Universal 1 (U1): ACG CGT CGA CAG AGT TTG ATC CTG GCT and Universal 2 (U2): CGC GGA TCC GCT ACC TTG TTA CGA CTT (Cinna Gene Company, Iran).

\subsection{Assay of Growth Kinetics and BLIS Biosynthesis}

The maximum BLIS production time was calculated using bacterial growth curves, according to the method described by Tahiri et al. (18). Using this method, the BLIS activity is expressed in arbitrary units per milliliter $(\mathrm{AU} / \mathrm{mL})$, and it detects the highest BLIS dilution that results in complete inhibition of the indicator strain.

\subsection{Effects of UV Light, $p H$, Heat, and Degenerative Enzymes on the Activity of BLIS}

The effects of UV light, $\mathrm{pH}$, heat, and degenerative enzymes on the BLIS activity of the best BLIS producer isolate were assayed. The BLIS antimicrobial activity of the indicator strain after the aforementioned treatments was assayed using the qualitative spot-on-lawn bioassay, as described above. The stability of BLIS in response to heat, $\mathrm{pH}$, and various degenerative enzymes containing proteinase $\mathrm{K}$ ( $\mathrm{pH} 7.0$ ), trypsin ( $\mathrm{pH} 7.0$ ), and pepsin ( $\mathrm{pH}$ 3.0) was investigated using a previously described method (18). To determine the effect of UV light on the activity of BLIS, $10 \mathrm{~mL}$ of filter-sterilized cell-free supernatant were placed in a sterile petri dish and exposed to UV irradiation at a distance of $25 \mathrm{~cm}$ for $5,10,15,20,25$, and 30 minutes. The activity of BLIS was then analyzed by the critical-dilution micromethod.

3.7. Partial Purification and Estimation of the Molecular Weight of BLIS by Sodium Dodecyl sulfate-Polyacrylamide Gel Electrophoresis (SDS-PAGE)

The selected BLIS producer was cultivated in trypticase soy broth, supplemented with $0.6 \%$ yeast extract for 24 hours at $30^{\circ} \mathrm{C}$. An antimicrobial potency production assay was performed using the spot-on-lawn method against $P$. aeruginosa ATCC 278531, as mentioned above. The sample was centrifuged at $16000 \mathrm{~g}$ for $10 \mathrm{~min}$ at $4^{\circ} \mathrm{C}$ and filter sterilized. BLIS was partially purified by subjecting the supernatant fluid $(\mathrm{pH}=6.5)$ to ammonium sulfate precipitation at final concentrations of $80 \% \mathrm{w} / \mathrm{v}$, as per the method described by Mirhosseini et al. (19). To estimate the molecular weight of BLIS, SDS-PAGE was used, as described previously (19).

\section{Results}

During a 12-month period, 96 P. aeruginosa isolates were obtained from different clinical samples. Table 2 summarizes some of the characteristics of the P. aeruginosa isolates. The results of the analysis of these 96 strains using WHONET 5.6 software showed that 2 (2.1\%), 94 (97.9\%), and 63 (65.6\%) isolates were non-MDR, MDR, and XDR, respectively, and 1 (1.1\%) isolate was PDR. Effective antibiotics against these isolates were colistin, polymyxin $\mathrm{B}$, and fosfomycin, with only $1 \%, 1 \%$, and $5.2 \%$ of isolates showing resistance, respectively, and high percentages of resistance were observed among the other antibiotics (Figure 1).

Two $P$. aeruginosa isolates had antimicrobial activity and showed large inhibition zones against the indicator organism P. aeruginosa ATCC 278531. One Pseudomonas isolate, which was identified as $P$. aeruginosa strain DSH22 based on its phenotypical and biochemical properties and 16SrRNA gene sequence, had potent BLIS production against the indicator organism and 92 (95.8\%) of the $96 P$. aeruginosa isolates, including the MDR, XDR, and PDR isolates. The production of BLIS was confirmed in neutralized supernatant of this isolate (data not shown).

Figure 2 presents the growth curves and profiles of BLIS production of the $P$. aeruginosa strain DSH22 (best BLIS producer). The results showed that the production of 
Table 2. Characteristics of the 96 Pseudomonas aeruginosa Strains Isolated Over a 12Month Period $(\mathrm{N}=96)$

\begin{tabular}{|c|c|}
\hline Parameters & Results \\
\hline \multicolumn{2}{|l|}{ Sex } \\
\hline Male & 63 \\
\hline Female & 33 \\
\hline \multicolumn{2}{|l|}{ Specimen type } \\
\hline Res & 37 \\
\hline $\mathrm{Bl}$ & 8 \\
\hline $\mathrm{Ur}$ & 29 \\
\hline Per & 3 \\
\hline sf & 2 \\
\hline $\mathrm{A} / \mathrm{W}$ & 10 \\
\hline $\mathrm{Dr}$ & 2 \\
\hline $\mathrm{Pl}$ & 2 \\
\hline Oth & 3 \\
\hline Ped & 5 \\
\hline Ger & 91 \\
\hline Inf & 4 \\
\hline \multicolumn{2}{|l|}{ Age category } \\
\hline Ped & 5 \\
\hline Ger & 91 \\
\hline \multicolumn{2}{|l|}{ Department } \\
\hline Inf & 4 \\
\hline Sur & 21 \\
\hline Eme & 10 \\
\hline Tra & 9 \\
\hline ICU & 44 \\
\hline Oth & 8 \\
\hline
\end{tabular}

Abbreviations: A/W, Abscess/wound; Bl, blood; Dr, Drain; Eme, emergency; Ger, geriatric; Inf, infectious disease; Oth, other; Ped, pediatric; Per, peritoneal; Pl, plural; Res, respiratory; sf, CSF; Sur, surgery; Tra, transplant; Ur, urine.

BLIS commenced in the midexponential phase of growth, and the maximum level $(2700 \mathrm{AU} / \mathrm{mL})$ occurred in the latestationary phase of growth after 25 hours of incubation at $30^{\circ} \mathrm{C}$.

As shown in Table 3, the BLIS activity of P. aeruginosa strain DSH22 was heat stable up to $100^{\circ} \mathrm{C}$ for 10 minutes but was sensitive to $121^{\circ} \mathrm{C}$ for 15 minutes (autoclave condition). It was active within the $\mathrm{pH}$ range of 3-9 (acidic/basic treats) but sensitive to $\mathrm{pH}=10$. It had UV stability after 30-min exposure, but its activity disappeared following exposure to trypsin, proteinase $\mathrm{K}$, and pepsin, indicating its proteinaceous nature.

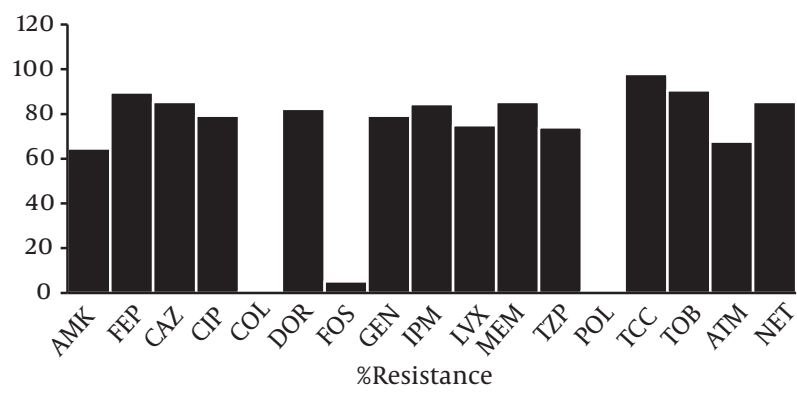

Figure 1. Resistance (\%) of Pseudomonas aeruginosa Strains to Different Antibiotics Obtained by WHOnet Software 5.6

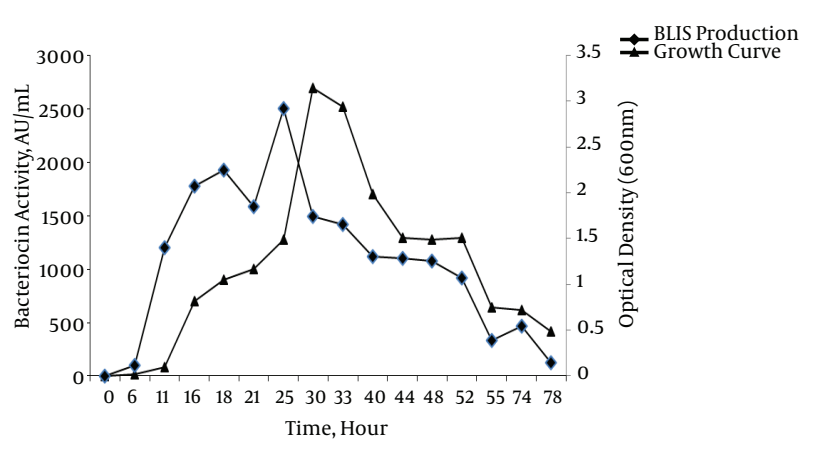

Figure 2. Growth Curve and BLIS Production of Pseudomonas aeruginosa Strain DSH 22 at $30^{\circ} \mathrm{C}$

The results of the SDS-PAGE of the partially purified BLIS are shown in Figure 3. The gel stained with Comassie Brilliant Blue showed protein bands and the molecular weight of the partially purified BLIS from P. aeruginosa strain DSH22. The molecular weight was approximately 25 $\mathrm{kDa}$ (Figure 3). In addition, the SDS-PAGE of BLIS overlaid with the indicator organism P. aeruginosa ATCC 278531 revealed a clear inhibition zone after 24 hours at $30^{\circ} \mathrm{C}$.

The analysis of the activity of BLIS against the other hospital-isolated pathogens demonstrated that it had no activity against either the gram-positive bacteria $S$. aureus, Enterococcus spp., and L. monocytogens or the gramnegative bacteria Klebsiella spp., Acinetobacter spp., and E. coli strains.

\section{Discussion}

Pseudomonas aeruginosa poses a serious threat to the treatment of both nosocomial infections and communityacquired infections. Unfortunately, the choice of the most appropriate antibiotic is difficult due to its ability to develop resistance to many classes of antibacterial agents, 
Table 3. Effect of Different Treatments on the Activity of BLIS Isolated From Pseudomonas aeruginosa DSH22

\begin{tabular}{|c|c|}
\hline Treatment & Activity, \% \\
\hline Control & 100 \\
\hline \multicolumn{2}{|l|}{ Degenerative enzymes } \\
\hline proteinase $K$, pepsin, and trypsin & 0 \\
\hline \multicolumn{2}{|l|}{ Heat } \\
\hline $60^{\circ} \mathrm{C}$ for $30 \mathrm{~min}$ & 100 \\
\hline $100^{\circ} \mathrm{C}$ for 10 and $20 \mathrm{~min}$ & 75 \\
\hline $100^{\circ} \mathrm{C}$ for $45 \mathrm{~min}$ & 50 \\
\hline $121^{\circ} \mathrm{C}$ for $15 \mathrm{~min}$ (autoclave condition) & 0 \\
\hline \multicolumn{2}{|l|}{ pH } \\
\hline 3 & 90 \\
\hline 5 & 90 \\
\hline $6-8$ & 100 \\
\hline 10 & 25 \\
\hline \multicolumn{2}{|l|}{ UV } \\
\hline 10,20 , and $30 \mathrm{~min}$ & 100 \\
\hline
\end{tabular}

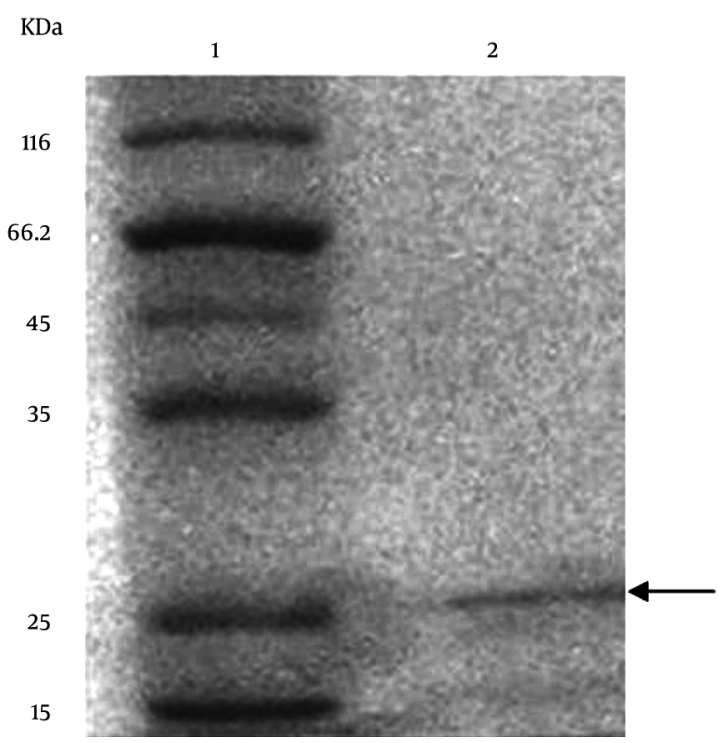

Figure 3. Band of SDS-PAGE of Partially Purified BLIS From Pseudomonas aeruginosa Strain DSH22 After Staining With Coomassie Brilliant Blue, Showing a Molecular Weight of Approximately $25 \mathrm{kDa}$. Line 1 is the Molecular Mass Marker (in kDa), and Line 2 is the Purified BLIS

even during the course of treating an infection (20). Epidemiological studies have shown that infections caused by drug-resistant strains of $P$. aeruginosa are associated with significant increases in mortality, morbidity, lengths of hospital stay or chronic care, need for surgical interventions, and overall costs of treating the infection (21). The emergence of PDR strains of $P$. aeruginosa, which are resistant to all current antibiotics, has led to concerted efforts to find alternative approaches to treatment, including older antibiotics that may have activity against these strains (22-25). In light of the increased antibiotic resistance of MDR microorganisms for which no adequate therapeutic options exist, a joint initiative by the ECDC and the CDC recently created standardized international definitions for MDR, XDR, and PDR in some bacteria. The aim of the initiative was to enhance the comparability of data and to improve understanding of the problem of highly drugresistant bacteria, in addition to finding the older effective antibiotics (14). In this study, we tested all ECDC and CDC recommended antibiotics against $P$. aeruginosa strains for frequency assessment of MDR, XDR, and PDR strains and finding effective antibiotics.

Wide studies followed the definitions proposed by the ECDC and the CDC for MDR, XDR and PDR determination in $P$. aeruginosa strains (22-28). For example, in a study by Gomila et al. (22), among 56 P. aeruginosa strains isolated in a Spanish hospital, 21.4\% were MDR, 37.5\% were XDR, and $41.1 \%$ were non-MDR strains. One non-PDR strain was isolated. In another study, 20 XDR $P$. aeruginosa isolates (10.5\% of all 190 analyzed isolates) were recovered from seven Spanish hospitals (23). In a study of 411 P. aeruginosa isolates in Asian hospitals, the MDR, XDR, and PDR rates of P. aeruginosa were $42.8 \%, 4.9 \%$, and $0.7 \%$, respectively (24). In a hospital in India, $84.7 \%$ P. aeruginosa isolates were MDR, of which $35.7 \%$ were XDR, and no PDR isolate was obtained (26). Mohanasoundaram et al. (27) reported a similar MDR rate $(71 \%)$ in a study in Tamil Nadu, India. In a study conducted in Pakistan, Gill et al. (28) reported that $22.7 \%$ of 180 P. aeruginosa isolates were MDR, whereas $11 \%$ and $4.3 \%$ were XDR and PDR, respectively. The present study is the first in Iran to examine the MDR, XDR, and PDR profiles of P. aeruginosa strains based on the definitions proposed by the ECDC and the CDC.

In the present study, among 96 isolates of P. aeruginosa, 2.1\%, 97.9\%, 65.6\%, and 1.1\% were non-MDR, MDR, XDR, and PDR, respectively, indicating very high MDR and XDR rates compared to the previously reported studies of $P$. aeruginosa isolates. In addition to polymyxins that in different studies their effective activity is confirmed for P. aeruginosa infections treatment, our study showed that fosfomycin had very good effect against $94.8 \%$ of the isolates. Unlike polymyxins, fosfomycin is well tolerated and has a low incidence of harmful side effects. However, the development of bacterial resistance under therapy is a frequent occurrence (28). Thus, it is not appropriate for continued therapy of severe infections, and it not recommended for chil- 
dren and the elderly (28).

The current study identified a novel BLIS produced by a $P$. aeruginosa strain, which showed extended-spectrum activity against MDR, XDR, and PDR P. aeruginosa strains. According to a study by Jack et al. (29), BLISs are similar to bacteriocins, except they have a lower molecular mass. Only a few BLISs have been identified, and the majority of those have been only partly purified and characterized. Similar to bacteriocin, the majority of BLISs are bacterial inhibitors (2, 30-33). Their bactericidal activity is usually directed against species that are closely linked to the producer microorganisms (2,30-33). The production of bacteriocin and similar substances, such as BLIS, can facilitate microbial survival in the human gastrointestinal tract (34).

A previous study demonstrated the ability of bacteriocin producers to inhibit pathogens in the gastrointestinal tract (35). Another study found that a Lactobacillus salivarius strain provided protection against Listeria monocytogenes infection in mice via production of a two-peptide bacteriocin and that a nonbacteriocin-producing isogenic derivative failed to protect mice from infection (36). The narrow spectrum of the action of bacteriocins limits the application of these peptides as antimicrobial agents or as food biopreservatives (2). The bacteriocins produced by Pseudomonas spp. (pyocins) have been extensively studied (13). For example, Parret et al. (13) reported novel lectin-like bacteriocins of a biocontrol strain P. fluorescens Pf-5 that were active against other strains of Pseudomonas. The BLIS isolated in the present study had extended-spectrum activity against MDR, XDR, and PDR strains of $P$. aeruginosa. This is the first report to describe the activity of these antimicrobial agents against PDR strains of this bacterium. No effective antibiotics against PDR strains exist, and there are very few effective antibiotics against XDR, other than polymyxins, which have a wide range of side effects. Thus, the isolated BLIS may be a good candidate antibiotic for the control of these strains.

The BLIS produced by $P$. aeruginosa strain DSH22 was inactivated by proteinase $\mathrm{K}$, pepsin, and trypsin enzymes, demonstrating its proteinaceous nature. The advantages of this BLIS are stability at a wide range of $\mathrm{pH}$ values, in addition to stability to heat and UV light exposure. UV resistance has been reported for other bacteriocins, such as the bacteriocin reported by Zaghian et al. (37) in Bacillus pumilus. However, UV resistance has not been reported previously for P. bacteriocins.

In the current study, the maximum level of antimicrobial activity was observed during the stationary phase of growth, similar to the findings of most other studies of bacteriocins $(15,31,38,39)$. The molecular weight of BLIS produced by P. aeruginosa strain DSH22 strain was approximately $25 \mathrm{kDa}$. Gram-negative bacteriocins can be divided into three groups based on their size (molecular weight) (40): large colicin-like (25 - $80 \mathrm{kDa}$ ) bacteriocins (2), much smaller microcins ( $<10 \mathrm{kDa}$ ), and phage tail-like bacteriocins, which are multimeric peptide assemblies $(2,37)$. Regarding this division, the isolated BLIS may be a novel BLIS belonging to large colicin-like bacteriocins.

In conclusion, the BLIS identified herein exhibited effective broad-spectrum activity. It may have potential as an alternative antibiotic for the treatment of drug-resistant strains of $P$. aeruginosa infections.

\section{Acknowledgments}

The authors are grateful to Sana Seyedipur, Fatemeh Khodabakhsh, and Afsaneh Shokri for their valuable help in editing this paper.

\section{Footnotes}

Authors' Contribution: Dariush Shokri contributed to all the laboratory experiments, study concept and design, interpretation of the data, and writing of the paper; Mohammad Rabbani Khorasgani: research and technical advisor, drafting of the manuscript, and final revision of the manuscript; Saeideh Zaghian contributed to some of the laboratory experiments; Seyed Masih Fatemi contributed to some of the laboratory experiments; Milad Mohkam contributed to some of the laboratory experiments; Younes Ghasemi: research and technical advisor; Asghar Taheri-Kafrani: research and technical advisor.

Funding/Support: This study was supported financially by the University of Isfahan and Iran National Science Foundation, Presidency of the Islamic Republic of Iran Vice-Presidency for Science and Technology (grant number: 92045033). All costs of this research project were provided from funds allocated for this project, and no fees were received from patients.

\section{References}

1. Ha DG, O'Toole GA. c-di-GMP and its Effects on Biofilm Formation and Dispersion: a Pseudomonas Aeruginosa Review. Microbiol Spectr. 2015;3(2):MB-3-2014. doi: 10.1128/microbiolspec.MB-0003-2014. [PubMed: 26104694].

2. Bierbaum G, Sahl HG. Lantibiotics: mode of action, biosynthesis and bioengineering. Curr Pharm Biotechnol. 2009;10(1):2-18. [PubMed: 19149587].

3. Rybalchenko OV, Bondarenko VM, Orlova OG, Markov AG, Amasheh S. Inhibitory effects of Lactobacillus fermentum on microbial growth and biofilm formation. Arch Microbiol. 2015;197(8):1027-32. doi: 10.1007/s00203-015-1140-1. [PubMed: 26267163]. 
4. Rasamiravaka T, Labtani Q, Duez P, El Jaziri M. The formation of biofilms by Pseudomonas aeruginosa: a review of the natural and synthetic compounds interfering with control mechanisms. Biomed Res Int. 2015;2015:759348. doi: 10.1155/2015/759348. [PubMed: 25866808].

5. Martinez FA, Dominguez JM, Converti A, Oliveira RP. Production of bacteriocin-like inhibitory substance by Bifidobacterium lactis in skim milk supplemented with additives. J Dairy Res. 2015;82(3):3505. doi: 10.1017/S0022029915000163. [PubMed: 25850555].

6. Ayed HB, Maalej H, Hmidet N, Nasri M. Isolation and biochemical characterisation of a bacteriocin-like substance produced by Bacillus amyloliquefaciens An6.J Glob Antimicrob Resist. 2015;3(4):255-61. doi: http://dx.doi.org/10.1016/j.jgar.2015.07.001..

7. Tapiba VM, Nasr NF, Higazy AM. Isolation, Identification and Application of Bacteriocin-Like Inhibitory Substances Producing Bacterial Strains. Int J Curr Microbiol App Sci. 2015;4(8):333-42.

8. Ghoul M, West SA, Johansen HK, Molin S, Harrison OB, Maiden MC, et al. Bacteriocin-mediated competition in cystic fibrosis lung infections. Proc Biol Sci. 2015;282(1814) doi: 10.1098/rspb.2015.0972. [PubMed: 26311664].

9. Joshi A, Grinter R, Josts I, Chen S, Wojdyla JA, Lowe ED, et al. Structures of the Ultra-High-Affinity Protein-Protein Complexes of Pyocins S2 and AP41 and Their Cognate Immunity Proteins from Pseudomonas aeruginosa. J Mol Biol. 2015;427(17):2852-66. doi: 10.1016/j.jmb.2015.07.014. [PubMed: 26215615].

10. Kaur S, Sharma P. Protease-Sensitive Inhibitory Activity of Cellfree Supernatant of Lactobacillus crispatus 156 Synergizes with Ciprofloxacin, Moxifloxacin and Streptomycin Against Pseudomonas aeruginosa: An In Vitro Study. Probiotics Antimicrob Proteins. 2015;7(2):172-80. doi: 10.1007/s12602-015-9188-4. [PubMed: 25693845].

11. Sahoo TK, Jena PK, Patel AK, Seshadri S. Purification and Molecular Characterization of the Novel Highly Potent Bacteriocin TSU4 Produced by Lactobacillus animalis TSU4. Appl Biochem Biotechnol. 2015;177(1):90-104. doi: 10.1007/s12010-015-1730-z. [PubMed: 26245257].

12. Woraprayote W, Pumpuang L, Tosukhowong A, Roytrakul S, Perez RH, Zendo T, et al. Two putatively novel bacteriocins active against Gramnegative food borne pathogens produced by Weissella hellenica BCC 7293. Food Control. 2015;55:176-84.

13. Parret $\mathrm{AH}$, Temmerman $\mathrm{K}$, De Mot R. Novel lectin-like bacteriocins of biocontrol strain Pseudomonas fluorescens Pf-5. Appl Environ Microbiol. 2005;71(9):5197-207. doi: 10.1128/AEM.71.9.5197-5207.2005. [PubMed: 16151105].

14. Magiorakos AP, Srinivasan A, Carey RB, Carmeli Y, Falagas ME, Giske CG, et al. Multidrug-resistant, extensively drug-resistant and pandrug-resistant bacteria: an international expert proposal for interim standard definitions for acquired resistance. Clin Microbiol Infect. 2012;18(3):268-81. doi: 10.1111/j.1469-0691.2011.03570.x. [PubMed: 21793988].

15. Donadio S, Maffioli S, Monciardini P, Sosio M, Jabes D. Antibiotic discovery in the twenty-first century: current trends and future perspectives. J Antibiot (Tokyo). 2010;63(8):423-30. doi: 10.1038/ja.2010.62. [PubMed: 20551985].

16. Forbes BA, Wesisfeld AS. Bailley and Scotte's Diagnostic Microbilogy. Chicago: Mosby; 2014.

17. Clinical and Laboratory Standards Institute. Performance Standards for Antimicrobial Disk Susceptibility Tests. Approved standard M2-A9. Clinical and Laboratory Standards Institute; 2014.

18. Tahiri I, Desbiens M, Benech R, Kheadr E, Lacroix C, Thibault S, et al. Purification, characterization and amino acid sequencing of divergicin M35: a novel class IIa bacteriocin produced by Carnobacterium divergens M35. Int J Food Microbiol. 2004;97(2):123-36. doi: 10.1016/j.ijfoodmicro.2004.04.013. [PubMed: 15541799].

19. Mirhosseini M, Nahvi I, Emtiazi G, Tavassoli M. Characterisation of anti-Listeria monocytogenes bacteriocins from Enterococcus faecium strains isolated from dairy products. Int J Dairy Technol.
2010;63(1):55-61. doi: 10.1111/j.1471-0307.2009.00543.x.

20. Chatterjee M, Anju CP, Biswas L, Anil Kumar V, Gopi Mohan C, Biswas R. Antibiotic resistance in Pseudomonas aeruginosa and alternative therapeutic options. Int J Med Microbiol. 2016;306(1):48-58. doi: 10.1016/j.ijmm.2015.11.004. [PubMed: 26687205].

21. Potron A, Poirel L, Nordmann P. Emerging broad-spectrum resistance in Pseudomonas aeruginosa and Acinetobacter baumannii: Mechanisms and epidemiology. Int J Antimicrob Agents. 2015;45(6):568-85. doi: 10.1016/j.ijantimicag.2015.03.001. [PubMed: 25857949].

22. Gomila M, Del Carmen Gallegos M, Fernandez-Baca V, Pareja A, Pascual M, Diaz-Antolin P, et al. Genetic diversity of clinical Pseudomonas aeruginosa isolates in a public hospital in Spain. BMC Microbiol. 2013;13:138. doi: 10.1186/1471-2180-13-138. [PubMed: 23773707].

23. Mulet X, Cabot G, Ocampo-Sosa AA, Dominguez MA, Zamorano L, Juan $\mathrm{C}$, et al. Biological markers of Pseudomonas aeruginosa epidemic high-risk clones. Antimicrob Agents Chemother. 2013;57(11):5527-35. doi: 10.1128/AAC.01481-13. [PubMed: 23979744].

24. Chung DR, Song JH, Kim SH, Thamlikitkul V, Huang SG, Wang $\mathrm{H}$, et al. High prevalence of multidrug-resistant nonfermenters in hospital-acquired pneumonia in Asia. Am J Respir Crit Care Med. 2011;184(12):1409-17. doi:10.1164/rccm.201102-0349OC. [PubMed: 21920919].

25. Akya A, Salimi A, Nomanpour B, Ahmadi K. Prevalence and Clonal Dissemination of Metallo-Beta-Lactamase-Producing Pseudomonas aeruginosa in Kermanshah. Jundishapur J Microbiol. 2015;8(7):ee20980. doi:10.5812/jjm.20980v2. [PubMed: 26421137].

26. Dash M, Padhi S, Narasimham MV, Pattnaik S. Antimicrobial resistance pattern of Pseudomonas aeruginosa isolated from various clinical samples in a tertiary care hospital, South Odisha, India. Am JRespir Crit Care Med. 2014;184(12):1409-17. doi: 10.4103/2278-0521.130200.

27. Mohanasoundaram $K$. the antimicrobial resistance pattern in the clinical isolates of Pseudomonas aeruginosa in a tertiary care hospital; 2008-2010 (A 3 year study). Clin Diagnost Res J. 2011;5(3):491-4.

28. Gill MM, Usman J, Kaleem F, Hassan A, Khalid A, Anjum R, et al. Frequency and antibiogram of multi-drug resistant Pseudomonas aeruginosa. J Coll Physicians Surg Pak. 2011;21(9):531-4. [PubMed: 21914408].

29. Jack RW, Tagg JR, Ray B. Bacteriocins of gram-positive bacteria. Microbiol Rev. 1995;59(2):171-200. [PubMed: 7603408].

30. Martinez JL, Baquero F. Interactions among strategies associated with bacterial infection: pathogenicity, epidemicity, and antibiotic resistance. Clin Microbiol Rev. 2002;15(4):647-79. [PubMed: 12364374].

31. do Nascimento Mda S, Moreno I, Kuaye AY. Antimicrobial activity of Enterococcus Faecium Fair-E 198 against gram-positive pathogens. Braz J Microbiol. 2010;41(1):74-81. doi: 10.1590/S1517838220100001000013. [PubMed: 24031466].

32. Nilsen T, Nes IF, Holo H. Enterolysin A, a cell wall-degrading bacteriocin from Enterococcus faecalis LMG 2333. Appl Environ Microbiol. 2003;69(5):2975-84. [PubMed: 12732574].

33. Zendo T, Eungruttanagorn N, Fujioka S, Tashiro Y, Nomura K, Sera Y, et al. Identification and production of a bacteriocin from Enterococcus mundtii QU 2 isolated from soybean.J Appl Microbiol. 2005;99(5):118190. doi: 10.1111/j.1365-2672.2005.02704.x. [PubMed: 16238749].

34. Dobson A, Cotter PD, Ross RP, Hill C. Bacteriocin production: a probiotic trait?. Appl Environ Microbiol. 2012;78(1):1-6. doi: 10.1128/AEM.05576-11. [PubMed: 22038602].

35. Lee JH, Karamychev VN, Kozyavkin SA, Mills D, Pavlov AR, Pavlova NV, et al. Comparative genomic analysis of the gut bacterium Bifidobacterium longum reveals loci susceptible to deletion during pure culture growth. BMC Genomics. 2008;9:247. doi: 10.1186/1471-2164-9-247. [PubMed: 18505588].

36. Corr SC, Li Y, Riedel CU, O'Toole PW, Hill C, Gahan CG. Bacteriocin production as a mechanism for the antiinfective activity of Lactobacillus salivarius UCC118. Proc Natl Acad Sci U S A. 2007;104(18):7617-21. doi: 10.1073/pnas.0700440104. [PubMed: 17456596]. 
37. Zaghian S, Shokri D, Emtiazi G. Co-production of a UV-stable bacteriocin-like inhibitory substance (BLIS) and indole-3-acetic acid hormone (IAA) and their optimization by Taguchi design in Bacillus pumilus. Ann Microbiol. 2012;62(3):1189-97. doi: 10.1007/s13213-0110359-6.

38. Acuna L, Picariello G, Sesma F, Morero RD, Bellomio A. A new hybrid bacteriocin, Ent35-MccV, displays antimicrobial activity against pathogenic Gram-positive and Gram-negative bacteria. FEBS Open Bio. 2012;2:12-9. doi: 10.1016/j.fob.2012.01.002. [PubMed: 23650575].

39. Shokri D, Zaghian S, Khodabakhsh F, Fazeli H, Mobasherizadeh
S, Ataei B. Antimicrobial activity of a UV-stable bacteriocinlike inhibitory substance (BLIS) produced by Enterococcus faecium strain DSH20 against vancomycin-resistant Enterococcus (VRE) strains. J Microbiol Immunol Infect. 2014;47(5):371-6. doi: 10.1016/j.jmii.2013.05.004. [PubMed: 23838264].

40. Brown CL, Smith K, McCaughey L, Walker D. Colicin-like bacteriocins as novel therapeutic agents for the treatment of chronic biofilm-mediated infection. Biochem Soc Trans. 2012;40(6):1549-52. doi: 10.1042/BST20120241. [PubMed: 23176515]. 